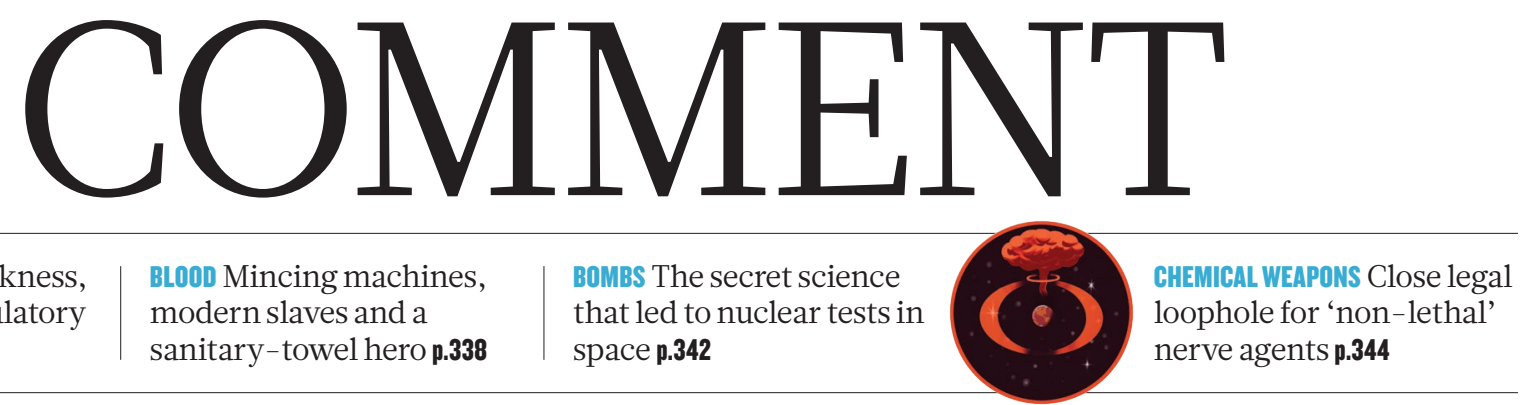

F00D A century of sickness, corruption and regulatory foot-dragging $\mathbf{p . 3 3 4}$

BLOOD Mincing machines,

sanitary-towel hero p.338
BOMBS The secret science that led to nuclear tests in space $\mathbf{p . 3 4 2}$ loophole for 'non-lethal' nerve agents $\mathbf{p . 3 4 4}$

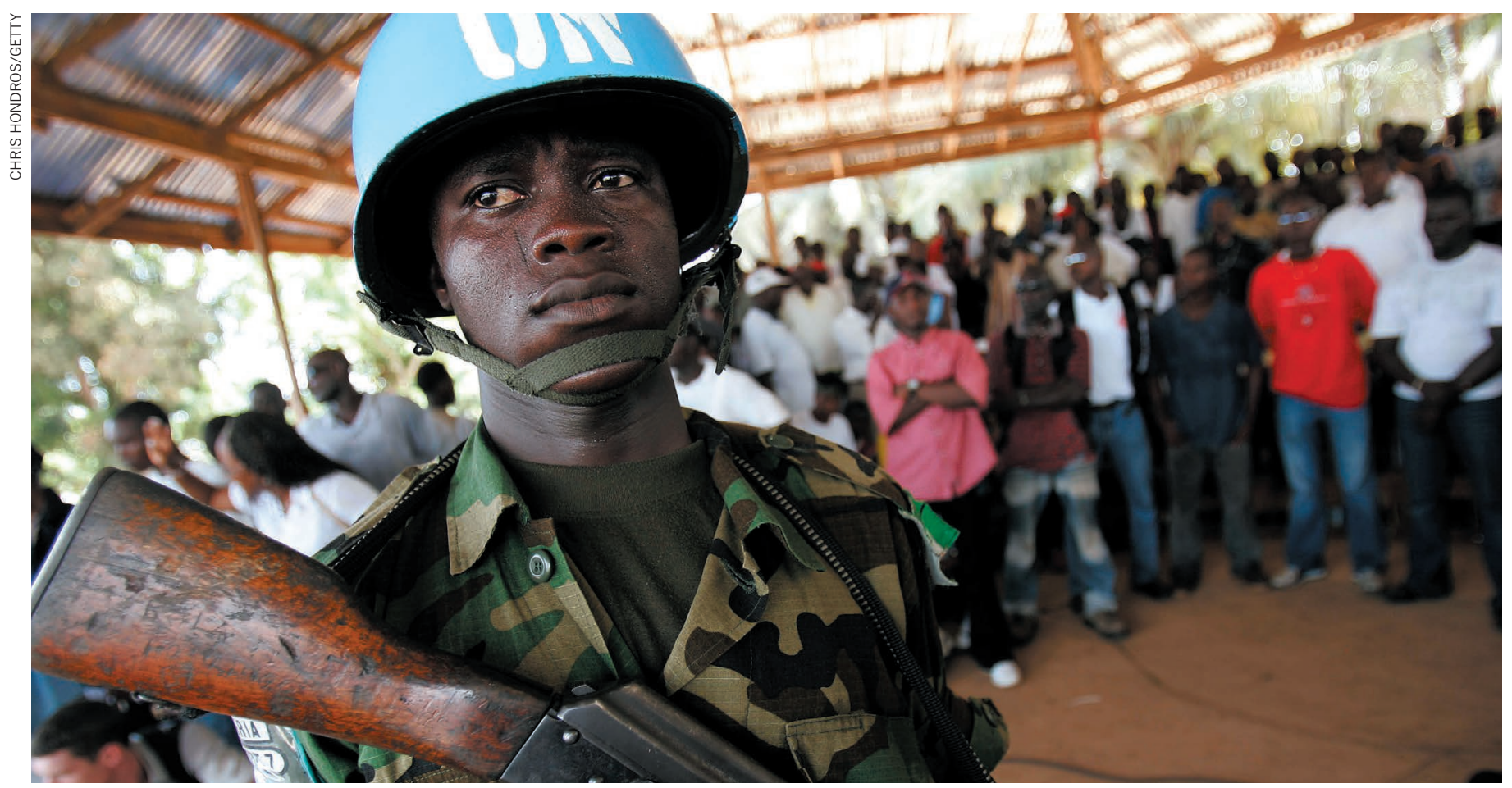

A UN peacekeeper at an election in Liberia in 2005.

\title{
Retool AI to forecast and limit wars
}

\section{Using artificial intelligence to predict outbursts of violence and probe their causes could save lives, argue Weisi Guo, Kristian Gleditsch and Alan Wilson.}

A rmed violence is on the rise and we don't know how to stop it ${ }^{1}$. Since 2011, conflicts worldwide have killed up to 100,000 people a year, three-quarters of whom were in Afghanistan, Iraq and Syria. The rate of major wars has decreased over the past few decades. But the number of civil conflicts has doubled since the 1960s, and terrorist attacks have become more frequent in the past ten years.

The nature of conflict is changing. Wars are waged less often between states, but increasingly within them by armed groups - more than 1,000 such groups operated in Syria at the peak of its civil war in 2013. They vary in size from a few local militias to tens of thousands of experienced fighters. Advances in technology makes attacks more precise, coordinated and deadly. Civilians are increasingly targeted. By 2016, wars had displaced more than 65 million people worldwide from their homes. More than half were children.

The costs are huge. The United Nations spent more than US\$20 billion in 2016 on humanitarian aid. Violent countries are weakened economically. For example, since 1996, wars have cost the Democratic
Republic of the Congo almost one-third of its gross domestic product ${ }^{2}$. Wars stifle progress towards many of the UN Sustainable Development Goals.

Nations spend relatively little on preventing conflicts. UN peacekeeping efforts in 2016-17 cost around \$7 billion, equivalent to less than $1 \%$ of global military spending. Yet peacekeepers have prevented conflicts from erupting in the wake of crises $^{3}$. For example, within one month of a disputed presidential election in Gambia in 2016, West African countries sent troops to maintain security. And interventions can stop them from 


\section{CONFLICT PREDICTION}

Armed conflicts differ in the degree to which they can be forecast.

\section{WHITE SWAN EVENTS}

Escalate on their own, follow statistical laws and can be predicted.

\section{VIOLENCE IN BAGHDAD, IRAQ (2001-14)} Each successful attack encouraged others in the same place.
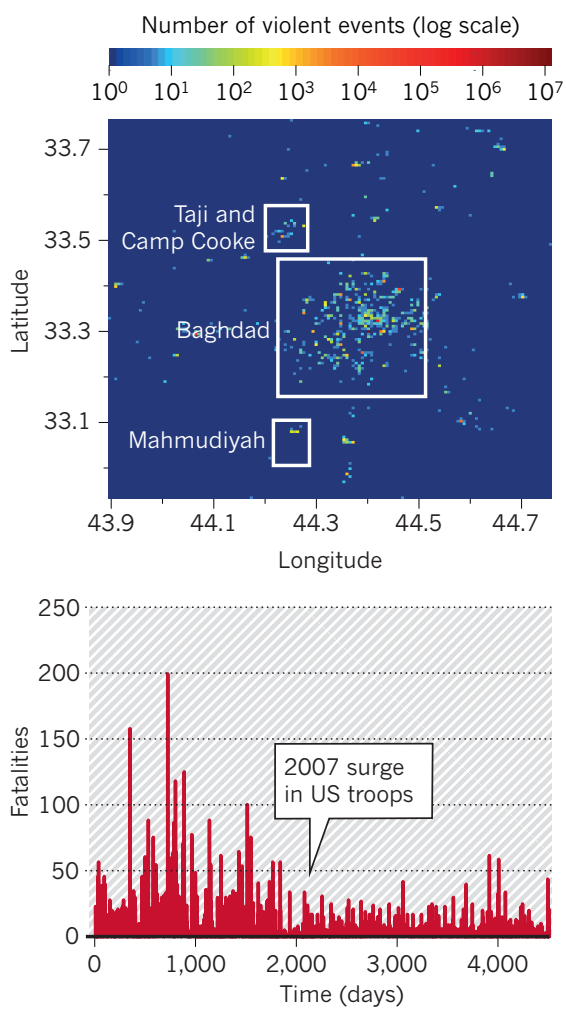

Prediction of fatality rates in Baghdad helped aid agencies and security forces.

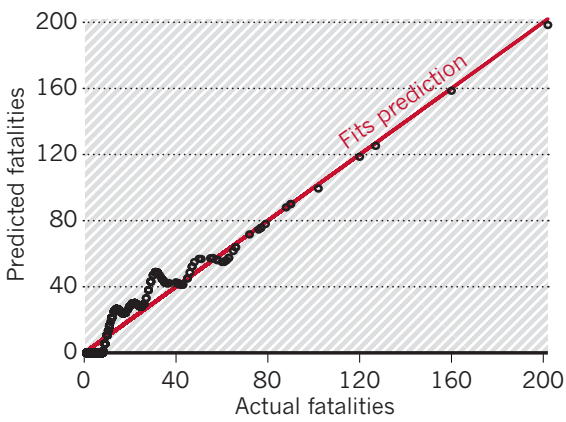

- recurring, as in El Salvador's civil war in 1991 and in Bosnia and Herzegovina in 1995.

Governments and the international community often have little warning of impending crises. Likely trouble spots can be flagged a few days or sometimes weeks in advance using algorithms that forecast risks, similar to those used for predicting policing needs and extreme weather. For conflict risk prediction, these codes estimate the likelihood of violence by extrapolating from statistical data ${ }^{4}$ and analysing text in news reports to detect tensions and military developments (see go.nature.com/2oczqep). Artificial

\section{BLACK SWANEVENTS}

Erupt without precedent, don't follow statistical laws and cannot be predicted.

\section{MASSACRE IN MAIDUGURI, NIGERIA (2015) Complex local events triggered unexpected} violence.

Number of violent events (log scale)
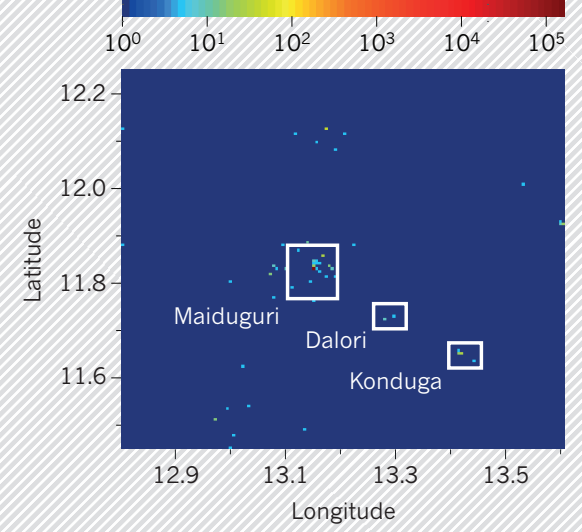

250

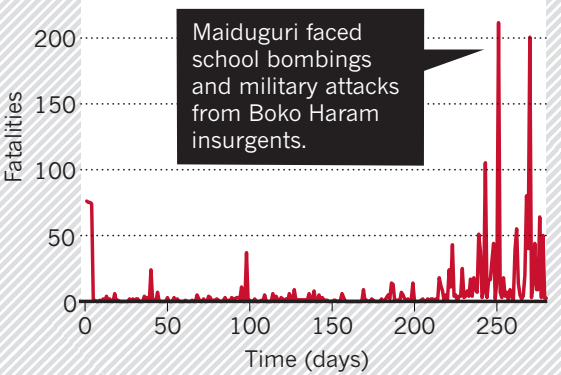

Maiduguri deaths could not have been predicted from previous conflicts, social media or news articles.

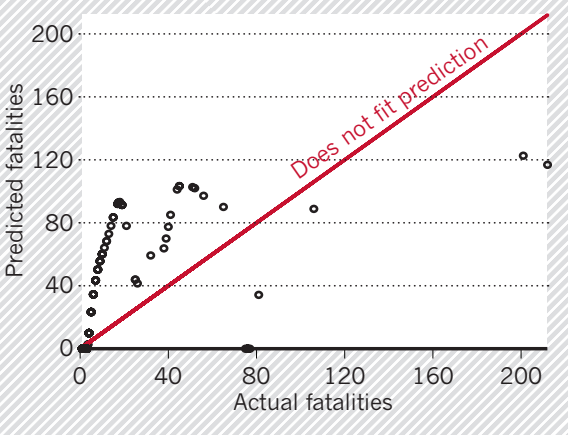

intelligence (AI) is poised to boost the power of these approaches.

Several examples are under way. These include Lockheed Martin's Integrated Crisis Early Warning System, the Alan Turing Institute's project on global urban analytics for resilient defence (run by W.G. and A.W.) and the US government's Political Instability Task Force.

Future AI and conflict models need to do more than make predictions: they must offer explanations for violence and strategies for preventing it. This will be difficult because conflict is dynamic and multi-dimensional.
And the data collected today are too narrow, sparse and disparate.

Three things will improve conflict forecasting. They are: new machine-learning techniques; more information about the wider causes of conflicts and their resolution; and theoretical models that better reflect the complexity of social interactions and human decision-making.

\section{BROADEN DATA COLLECTION}

Conflict prediction took off in the 1920s and 1930s. One of its pioneers was mathematician Lewis Fry Richardson, who applied statistics to study the causes of wars ${ }^{5}$. He revealed certain rules, such as that there are more small fights that kill a few people than large ones in which many die. Gang murders in Chicago in Illinois and Shanghai, China, followed the same scaling laws as major wars, he found. These laws tell us roughly how many skirmishes to expect, but not where or when they might occur.

Data collection has marched on. Fatalities, locations, actors and objectives for hundreds of thousands of battles and attacks are recorded in databases such as the Armed Conflict Location and Event Data Project (www.acleddata.com), the Global Terrorism Database (www.start.umd.edu/gtd) and the Uppsala Conflict Data Program (http://ucdp. uu.se). The data come from many sources, often media reports, and are checked by human specialists. They are good enough to give authorities a few days' notice of worse to come, but not the weeks or months of warning that are needed to devise strategies for peaceful resolutions.

The types of data collected, and the predictive models, are too crude to reveal the social drivers of conflict. Sometimes the most important outcomes are unobservable: incidents that were deterred or thwarted by security forces or back-door political bargaining. Media reporting of violence is stifled in countries such as Iran. Actors can shift tactics and allegiances. Violent factions might stoke tensions in the background while pursuing peace in public, as in Northern Ireland during the Troubles (1966-1998) and in Colombia since 1964.

Levels of violence depend on intangibles such as the willingness to fight. Weapons and funds from sources outside the country intensify civil conflicts, as in Syria and Yemen. Successful attacks encourage further attempts. Inequality, ethnic tensions or oppressive governance can trigger riots or civil wars. Environmental factors such as drought add to all these pressures.

\section{REDUCE UNKNOWNS}

AI will add little if social and causal factors are omitted. Furthermore, the statistical approaches used today for machine learning cannot deal with such a mix of unknown information. For instance, AIs need to be 


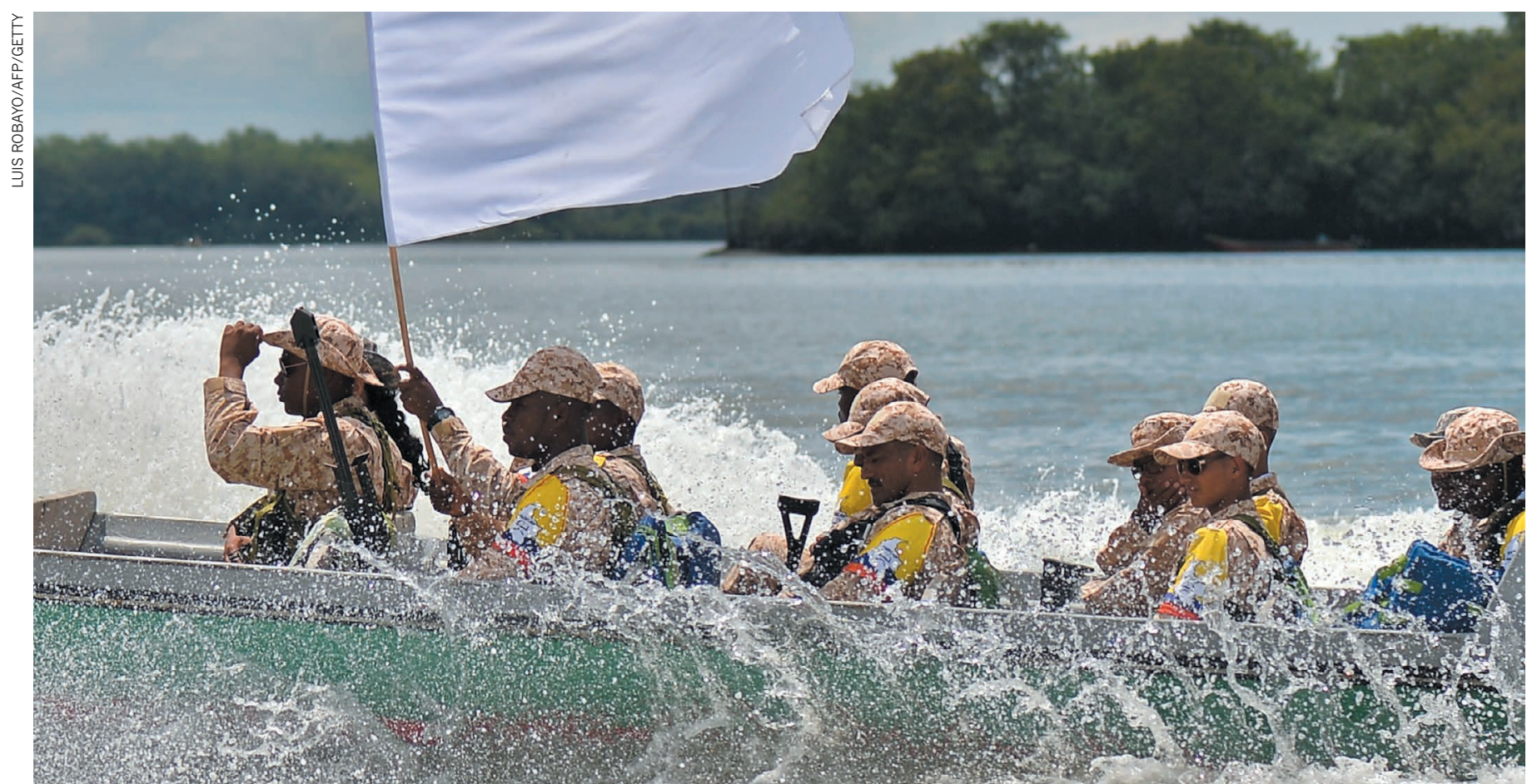

Members of the FARC guerrilla group in Colombia began a disarmament process in 2017.

trained to make inferences. They 'learn' from existing data, test whether predictions hold, and then hone the algorithms accordingly. This assumes that the training data mirror the situation being modelled. The problem is that, often, we do not know whether they are similar or not, especially in evolving scenarios that involve many hidden factors. If they don't, then the predictions are unreliable.

More needs to be learned about the statistics of different types of conflict; we already know that there are differences (see 'Conflict prediction'). For example, separatist ethnic conflicts are more likely to stay within a homeland than spread beyond it. Terrorist attacks are more common in civil wars than in invasions. Elaborate attacks requiring planning, such as the terrorist strikes on New York's World Trade Center on 11 September 2001, are most likely to occur outside a conventional conflict.

\section{DEVELOP THEORIES}

Conflict researchers have yet to develop a universally agreed framework of theories to describe the mechanisms that cause wars. Such a framework would dictate which sorts of data are collected and what needs to be forecast. Most current studies test data against simple informal hypotheses, such as that climate change increases violence. Correlations are sought; models disagree; the results are contentious ${ }^{6}$. Too few questions are asked about context, such as political and economic inequalities or military deterrence.

Modelling complexity will be key. For example, where is it best to intervene for a peaceful outcome, and how much intervention is needed? Algorithms could tease out spatial patterns from interacting stakeholders ${ }^{7}$, or highlight unstable geographical boundaries using the theory of social competition between neighbouring groups $^{8}$. For example, a team including one of us (A.W.) used such models ${ }^{9}$ to characterize the London riots in 2011 after the event. The work confirmed the police numbers that were required to restore order. However, models such as these are only as good as the data that go into them.

\section{A GLOBAL CONSORTIUM}

Conflict prediction and prevention need a global data-driven system, like those for forecasting weather, epidemics and maintenance needs in engineering. We propose that an international consortium be set up to develop formal methods to model the steps society takes to wage war. Establishing this platform would cost tens of millions of dollars, a fraction of the billions that the world pays to cope with conflict.

The consortium should involve academic institutions, international and government bodies (such as the European Commission Disaster Risk Management Knowledge Centre, UN Peacekeeping and national foreign offices) and industrial and charity interests in reconstruction and aid work (such as the engineering and construction consultancy Arup, and the International Red Cross and Red Crescent Movement). Academic researchers should set up a virtual global platform for comparing AI conflict algorithms and socio-physical models ${ }^{10}$. This must use open-access data to accelerate reproducible research and to benchmark outputs. Standards for measurements, theories and models need to be developed.

We hope to take the first steps to agree a common data and modelling infrastructure at a workshop on 15-16 October. The event, organized by Uppsala University in Sweden, will focus on the Violence Early-Warning System (ViEWS; see go.nature.com/2y7b9qt). We call on the UN to invest in data-driven predictive methods for promoting peace.

Weisi Guo is a Turing Fellow and associate professor in the School of Engineering, University of Warwick, Coventry, UK. Kristian Gleditsch is professor of political science in the Department of Government, University of Essex, Colchester, UK. Alan Wilson is director of special projects at the Alan Turing Institute, London, UK. e-mail:weisi.guo@warwick.ac.uk

1. World Bank \& United Nations. Pathways for Peace: Inclusive Approaches to Preventing Violent Conflict (World Bank \& United Nations, 2018).

2. IANSA, Oxfam \& Saferworld. Africa's Missing Billions (IANSA, Oxfam \& Saferworld, 2007).

3. Hegre, H., Hultman, L. \& Nygard, H. Peacekeeping Works: An Assessment of the Effectiveness of UN Peacekeeping Operations (Peace Research Institute Oslo, 2015).

4. Zammit-Mangion, A., Dewar, M., Kadirkamanathan, V. \& Sanguinetti, G. Proc. Natl Acad. Sci. USA 109, 12414-12419 (2012).

5. Richardson, L. F. Nature 155, 610 (1945).

6. Adams, C., Ide, T., Barnett, J. \& Detges, A. Nature Clim. Change 8, 200-203 (2018).

7. Turchin, P., Currie, T. E., Turner, E. A. L. \& Gavrilets, S. Proc. Natl Acad. Sci. USA 110, 16384-16389 (2013).

8. Lim, M., Metzler, R. \& Bar-Yam, Y. Science 317, 1540-1544 (2007).

9. Davies, T. P., Fry, H. M., Wilson, A. G. \& Bishop, S. R. Sci. Rep. 3, 1303 (2013).

10.Caldarelli, G., Wolf, S. \& Moreno, Y. Nature Phys. 14, 870 (2018) 